\title{
Effect on CI Engine Piston by Waste Cooking Oil Biodiesel
}

\author{
Adhirath Mandal*, HaengMuk Cho*,*** and Bhupendra Singh Chauhan** \\ * Div. of Mechanical Engineering, Kongju National University, Republic of Korea \\ ** Department of Mechanical Engineering, GLA University, Mathura, Uttar Pradesh, India \\ ***Corresponding Author : hmcho@kongju.ac.kr
}

\begin{abstract}
The major contributor of pollution in the environment has been because of the transportation sector. Compression ignition engine has been a popular engine in the transportation sector. Compression ignition engines have been very popular in the power plants and marine engine because of its high compression ratio. Compressors and reciprocating engine(cylinder-piston) are the mechanical assembly in an IC engine. Change in air fuel mixture in the cylinder improves the combustion and emission. Rising concern for the environmental emission, strict rules have been implemented because of which automobile manufactures have to modify the engine to suit better the emission standards. Depleting fossil fuels and rising emission standards, biodiesel blend has gained interest as an alternate fuel, for being used in CI engine. Biodiesel could be produced from waste and non-edible oils, shows similar properties to conventional diesel fuel. Waste cooking oil as biodiesel have gained interest in the researchers. Employing waste cooking oil biodiesel in a $\mathrm{CI}$ engine, it was important to analyses the effect on cylinder and piston. This paper analyses and compares the thermal effect of the waste cooking oil biodiesel with conventional diesel on the piston of a CI engine.
\end{abstract}

Keywords: Biodiesel; Waste cooking oil biodiesel; CI engine; Piston; Cylinder; Thermal analysis.

\section{INTRODUCTION}

Transportation sector majorly uses compression ignition engine, higher compression ratio which is one of the reason the diesel engine has better efficiency than gasoline engine. As our living standards are changing towards a positive side, more people are buying vehicles. This is leading to increase in vehicular population $\&$ as the vehicle are increasing the consumption of fossil fuels are also increasing. Increase in fossil fuel consumption leads to the reduction of the fossil fuels and raise in the emissions by the vehicles. We have been dependent on the fossil fuels for years \& the use of fossil fuels continuously would deplete it, which would be harmful for the environment. To avoid these conditions, research on efficiency, compression ration of the diesel engine are being carried out. Many researches are being achieved in the field of alternative fuels. Biodiesel being a part of alternate fuels, slowly it started gaining industry in the automobile industry. Biodiesel is being researched because of this no sulphur content, and apart from this biodiesel has built in oxygen of about $10-11 \%$ and has a better combustion because of higher cetane number. But apart from having such great advantages biodiesel has a big disadvantage of having higher NOx emission. Apart from all these, biodiesel have similar characteristics like the conventional diesel fuel (Rajesh Govindan at al., 2014, Ahmed A. Al-Harbi et al., 2020).Cylinder and piston are the principal components where the combustion occurs, power is generated for the movement of the vehicle. Piston is one of the most significant element in an engine, because it absorbs a lot of pressure during combustion. Thermal force and mechanical force act on the piston. Power of the IC engine is limited by the resistance offered by mechanical and thermal force acting on the piston. Therefore design of 
the piston is very important, as it would define the load and stress on the piston (V G Cioată et al., 2017). As diesel and waste cooking oil biodiesel have similar properties, they can be used in the same compression ignition engine. It is essential to calculate the combustion impact of biodiesel on the piston.

Combustion chamber and piston would have the same material and use of biodiesel instead of diesel would result change in temperature and stresses on the piston. Therefore temperature of the piston was an important criteria. Therefore computation of the temperature at the piston will help us in calculating the life of the piston and the deformation on the piston. The accurate temperature of the piston would be difficult to measure because of high temperature, transient interaction of the gas and the solid wall, and high turbulent flow (Mika Nuutinen et al., 2008, Asif Afzal et al., 2018).

In this paper a piston was built with the help of a CAD design Software, which was further used to analyse the thermal stresses on the piston with the help of a CFD tool. The design created in Solidworks 2018 and Ansys fluent was employed for analysis. With the help of the analysis, first the temperature on the piston was calculated and then the temperature was used on the piston to analyses the steady state thermal analysis of the piston. Through steady state thermal analysis we were able to find the thermal stress points. Temperature results of conventional diesel fuel were compared with waste cooking oil biodiesel.

\section{LITERATURE REVIEW}

A.R. Bhagat et al. discussed about the stress distribution with the help of finite element analysis on a piston of a four stroke engine. Finite element analysis was executed with the help of computer aided design software. The main aim for the study was to examine the thermal stress distribution in the piston when the combustion process was being carried out i.e. real condition.

Using the finite element analysis the mesh was optimized so that better critical regions and higher stress in the piston could be analyzed. To reduce the stress concentration, optimization was carried out on the sleeve, piston skirt and on the piston head. From the analysis it was concluded that the pistons upper end may have some cracks which were caused by the deformation of the piston skirt. Most of the stress was focused on the upper end of the piston because of the deformation. Piston having lower stiffness the situation were more serious as at that point the crack appeared and slowly leads to splitting of the piston verticals. Maximum stress changed from 228Mpa to $89 \mathrm{Mpa}$, depicted by the FEA analysis and deformation was reduced from $0.419 \mathrm{~mm}$ to $0.434 \mathrm{~mm}$.

Shoichi Furuhama et al. temperature and thermal correlations in the piston ring and piston are very difficult to measure and especially under operating conditions. Heat flow rate and flow pattern was used to find conflicts between the oil ring, second ring and the top ring, and also differences between the taper faced rings and the plain rings by the help of experiment. It was observed in the condition of the plain ring, temperature was symmetrical on both the sides, i.e the upper and lower. In the first ring the heat flow is from the inner to the outer. Difference of $40^{\circ}$ was noted between the inner and outer ring. In condition of the taper ring the ring twisted in the operating condition. The heat flow to the sides is higher, the ends of the ring becomes hot and the heat concentrates therefore the ring twists. In the oil ring the temperature was symmetrical and almost $70 \%$ heat flows into the oil. It was related that only $5 \%$ to $10 \%$ heat of combustion flow into the piston crown and almost $70 \%$ of the heat flows through the ring zone.

Dallwoo Kim et al. studied about the piston. Iron piston was used in the diesel trucks because of large power requirements but these pistons had a common problem of expansion for this reason lubrication conditions were studied for steel piston and cast iron piston. Aluminum pistons which were the conventional use were also observed and friction was measured \& compared with other pistons. Temperature of the iron piston was measured and was around $2300 \mathrm{C}$ and at the same time aluminum piston was $1550 \mathrm{C}$, stainless steel the temperature was $2100 \mathrm{C}$ when the temperature was $100 \mathrm{kPa}$. The piston temperature was measured to compare the frictional forces among the different piston materials and the friction because of the expansion rate of the piston. Ajay V. Kolhe et al. developed a model to analyze the combustion in a DI diesel engine fueled biodiesel-diesel blend of Pongamia Pinnata. Cylinder combustion 
was modeled with finite rate chemistry and species transport. Heat release rate by biodiesel blend in the case of simulation was $30 \mathrm{~J} / \mathrm{s}$ but during experiment it was found to be $25 \mathrm{~J} / \mathrm{s}$ at a crank angle of 3640 , where as in the case of diesel the heat release predicted by simulation was $34.41 \mathrm{~J} / \mathrm{s}$ but during experiment it was found to be $27 \mathrm{~J} / \mathrm{s}$ at 3640 crank angle. Figure $1 \&$ Figure 2 shows the Heat release rate, pressure rise and incylinder pressure showed similarity, of the experimental and simulated data. Hidehiko Kajiwara et al. studied on the piston of a diesel engine, its thermal loading increment. Temperature of the piston at the combustion bowl edge, top land \& top ring groove were 324, 251 \& 189 respectively from simulation and 330, $256 \& 195$ by experiment, as shown in figure 3.

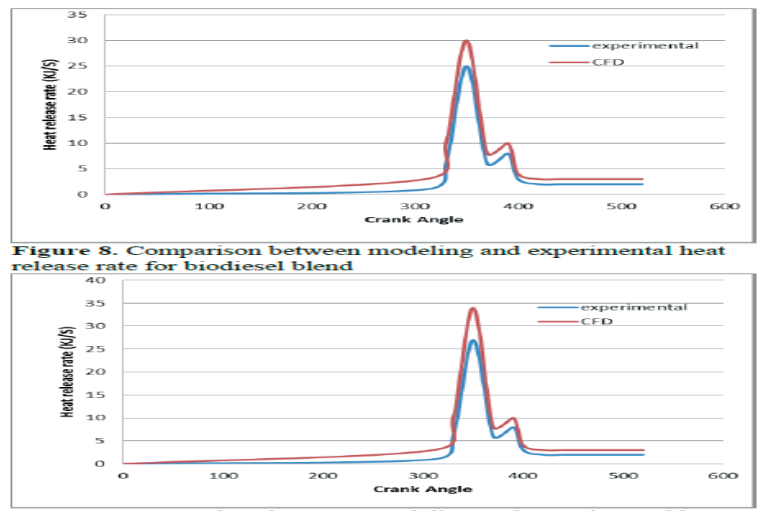

Figure 1. Comparison between modeling and experimental heat release rate for biodiesel blend (Ajay V. Kolhe et al., 2015)

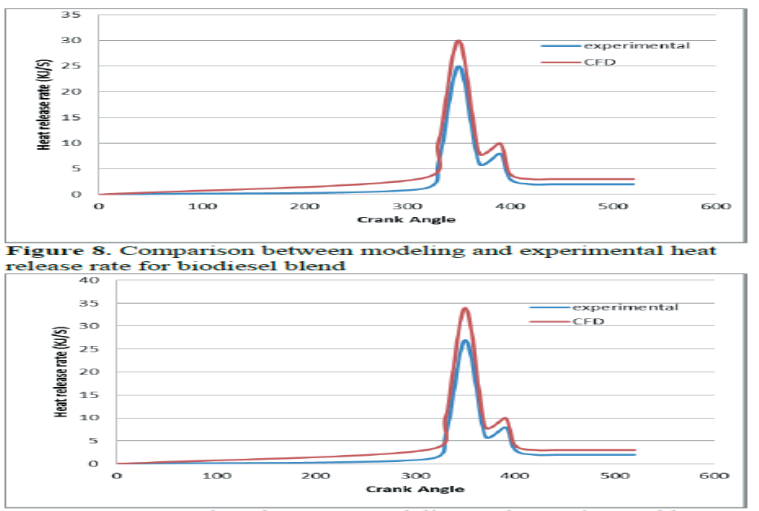

Figure 2. Comparison between modeling and experimental heat release rate for Diesel (Ajay V. Kolhe et al., 2015)

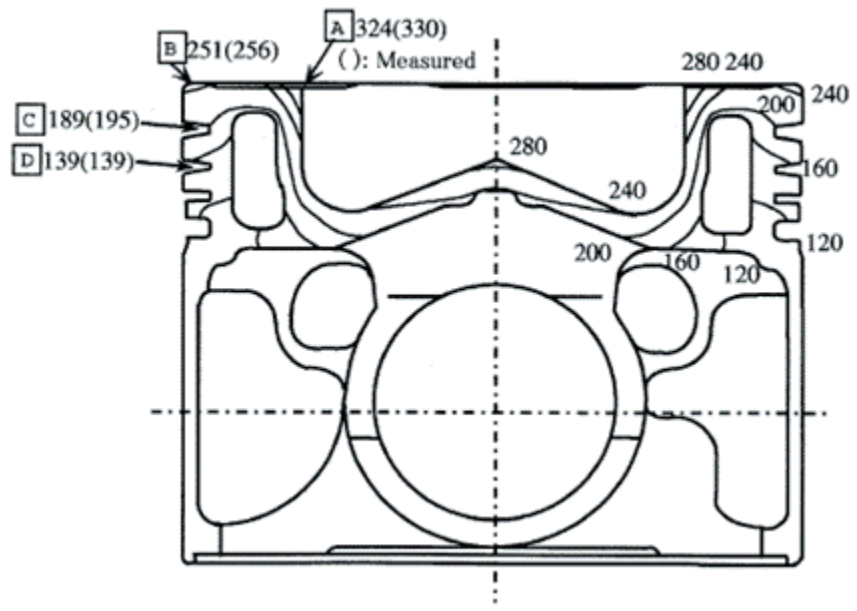

Figure 3. Temperature Distribution (Hidehiko Kajiwara et al., 2002) 
The prediction were almost similar through simulation. Magín Lapuerta et al. researched on two different biodiesel which were obtained from waste cooking oil. The two different biodiesel were methyl ester and ethyl ester, both were alcohol driven. Biodiesel was tested as pure and in a blend of $30 \%$ \& $70 \%$ volume basis. European drive cycle was used to simulate the operation mode. Pure biodiesel resulted in increase in fuel consumption compared to reference fuel. With use of biodiesel $\mathrm{NO}_{\mathrm{x}}$ emission was reduced slightly, but in case of smoke opacity, total hydrocarbon emission, particle emission there was sharp reduction, although volatile organic fraction of the particulate matter increased. Alcohol type used in the production of biodiesel showed effect in the hydrocarbon emissions and particulate matter composition. Volatile organic fraction of the particulate matter \& Hydrocarbon emissions and were observed to increase. Engine test were performed in the European drive cycle under medium load and under load conditions with $100 \%$ biodiesel and blends of ethyl ester and methyl blends. The results observed from these conditions showed that particulate matter, smoke opacity and hydro carbon emission was reduced to great extent by using waste cooking oil biodiesel fuel. Cheng Tung Chong et al. experimented by using pool flames using extinction calibrated laser induced-incandescence (LII) and pre-vaporised diffusion jet flames under total carbon flow to compare and quantify the soot volume fraction of waste cooking oil biodiesel and its bled. Soot is formed highest at the flame and convected downstream for diesel fuel, but in the condition of biodiesel, soot volume fraction is the center of the flame was evenly distributed. Soot tendency reduced by increasing the biodiesel fraction which was visible in vapour flame and pool flame. SVF profiles for pool flame was noticed when radial profile of SVF was compared along the centerline, residence time for soot diffusion and growth compared to vapour flame was reflected, this showed that the pool burner had low mass flux. At higher temperature the diesel rich fuel flame soot was found which convert quickly upwards. $62.9 \mathrm{~nm}$ (pool) for biodiesel and 51.6 for diesel. Soot produced was higher in the vapour flame than pool flame by a factor of two, mass consumption rate for same fuel. Soot volume fraction for waste cooking oil biodiesel was lowest irrespective of the flame type and owing to fuel chemistry and aromatic compound absent. The diameter of soot primary particle size was 1.5 lower mean diameter for waste cooking oil biodiesel than diesel produced soot. Large diameter particles of $22 \%$ was produced for diesel by pool flame and $8 \%$ for biodiesel. Ali M.A. Attia et al. produced biodiesel from waste cooking oil by transesterification process, waste cooking oil methyl ester (WCOME). Experimental evaluation of engine performance on different WCOME and conventional diesel blend were tested. Effect on soot tendency and viscosity was investigated conventional diesel blend were tested. Effect on soot tendency and viscosity was investigated by the use of waste cooking oil biodiesel and its blend with diesel. The performance of the engine was measured at an RPM of 1500 and at different engine load, in terms of engine and environmental aspect and in-cylinder pressure. It was observed that biodiesel blend ratio and engine load decides the in-cylinder peak pressure. Use of B20 depicted best value of BTE and brake specific energy consumption. With blend ratio from B20 to B50, all were best for the engine environmentally. BSEC increased by $8 \%$ by the use of neat biodiesel fuel at different load of the engine, engine smoke opacity increased by $15 \%$ but NOx emission decreased by $10 \%$, unburnt hydrocarbons decreased by $15 \%$ and carbon monoxide decreased slightly. $30 \%$ to $50 \%$ blending ratio was recommended for better engine performance and emission improvement. With the biodiesel blend BSFC was $10 \%$ higher, $\eta$ bth had no change, BSEC had 3\% change and TExh was lower by $2 \%$ where as smoke opacity was high by $20 \%, 6 \%$ reduced NOx, CO lower by $25 \%$ and UHC by $20 \%$. S. Senthur Prabu et al. studied on the use of waste cooking oil with hydroxytoluene and n-butanol additive. Exhaust emission and engine performance was evaluated. Sodium hydroxide, sulphuric acid and methanol was used as catalyst reaction for transesterification process of waste cooking oil to biodiesel. B0, B20, B30, B40 \& B100 biodiesel blends, tested the engine performance. It was observed that $\mathrm{B} 30$ was the best blend between the other biodiesel blends. n-butanol $20 \%$ by volume and antioxidants of BHT 2000 was added to improve the performance of B30 fuel blend. Brake thermal efficiency was lower than diesel by $4.6 \%$ but brake specific fuel consumption was $7.3 \%$ higher for $\mathrm{B} 30$ +butylated hydroxytoluene. Heat release were same as diesel for B20,B40 and B30+BHT blend but B30+butanol at higher load showed higher heat release rate than diesel. Cylinder pressure for B30 was less by $4.5 \%$ where as for other blends the cylinder pressure were same as diesel fuel. B30+n-butanol showed higher EGT (2.3\%) \& NOx (9\%) compared to diesel fuel but Co emission was less by $37.5 \%$. Compared to diesel fuel the $100 \%$ biodiesel had $51 \%$ lesser exhaust gas temperature. Performance of the engine on BTE and BSFC reduces steadily as the biodiesel fraction increase in the blend as shown I figure $4 \&$ figure 5. B30 showed better emission characteristics than diesel fuel. 


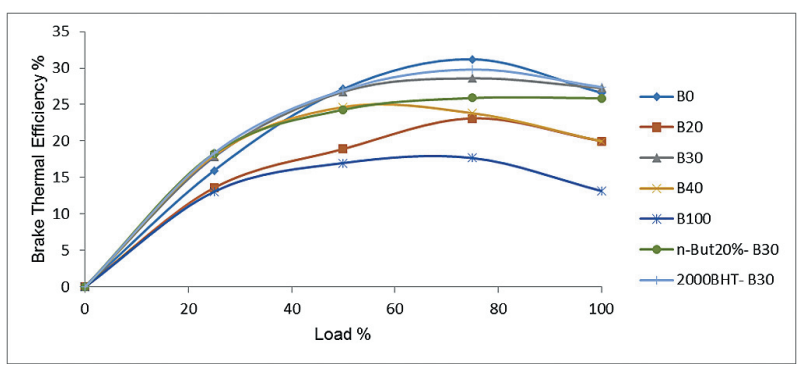

Figure 4. Brake thermal efficiencies of different blends at different loads (S. Senthur Prabu et al., 2017)

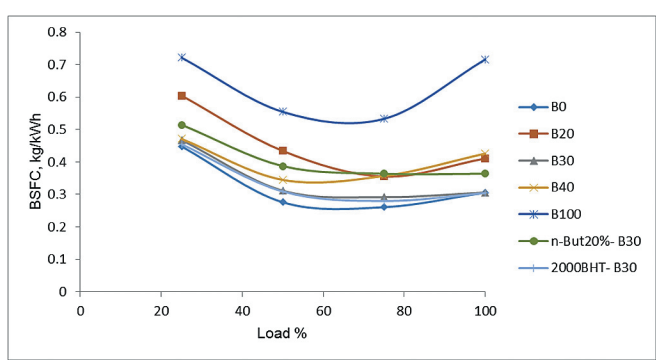

Figure 5. Brake specific fuel consumption of different blends at different loads

(S. Senthur Prabu et al., 2017)

Daniel P. Madison et al. researched and compared the piston temperature which was measured by metallurgical temperature sensor and also by thermocouples. The metallurgical temperature were analyzed one by one, after the test was complete. The temperature of the piston bowl are was between $2150 \mathrm{C}$ to $1980 \mathrm{C}$, when measured with the thermocouple and 2370C to 1980C when measured with the templug [9]. Mahdi Hamzehei et al. researched that the efficiency, performance and the emission of a SI engine have influence of the temperature on the cylinder head and the piston. Authors main aim was to measure the transient temperature at different points on the cylinder head and piston, for cold start to steady conditions. Temperature on the cylinder head was measured at 5 different points and in case of the piston it was measured at 10 different points. Reduce the noise and sparkplug interference, low pass filters were designed. Temperature variation were observed at different points on the cylinder head and piston. The temperature variation was there with engine speed and time. J.H. Ong. Discussed about the use of finite element analysis analysis, to be used in high speed diesel engine for the prediction of temperature, with steady state temperature distribution was carried out. Neglecting circumferential temperature, Y-Axisymmetric modelling was conducted. Analysis was carried on MSC/Nastran. 2780C was the temperature on the piston, and good correlating was obtained between simulated data and experimental data.

\section{DESIGN DATA}

Piston head with flat head was considered for the study of the temperature on the piston. Establishment of the piston design data and the materials data was from the literature review. 3D model was established of the piston design data from the literature review. Silicon based aluminum alloy was regarded as the material for the piston. Eutectic alloy (ATC12CuMgNi) which is the material of the piston, its material properties have been listed in table 1 (V G Cioată et al., 2017). CAD file of the piston was produced with the help of Solidworks 2017 as shown in Figure 7. Cad file were transferred to Ansys workbench 16 for analysis. Temperature of combustion was calculated with the help of Ansys fluent model. Finite element analysis was used to build the combustion model.

Table 1. Piston Material properties.

\begin{tabular}{|c|c|}
\hline Thermal Expansion & $2.3 \times 10^{-5} 1 /{ }^{\circ} \mathrm{C}$ \\
\hline Thermal conductivity & Figure 6 \\
\hline Specific Heat & $875 \mathrm{~J} / \mathrm{Kg}^{\circ} \mathrm{C}$ \\
\hline Density & $2770 \mathrm{Kg} / \mathrm{m}^{3}$ \\
\hline
\end{tabular}




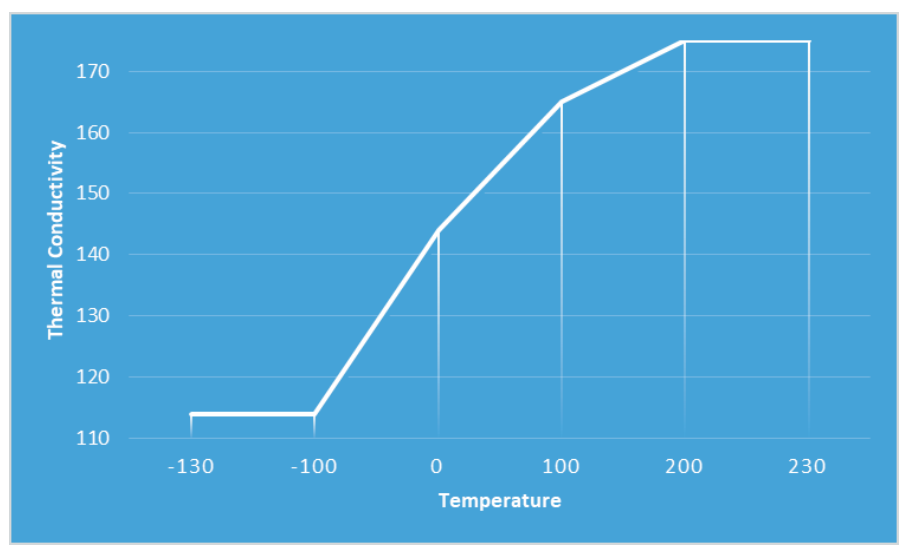

Figure 6. Thermal Conductivity of piston materia

\section{FUELS}

Two different fuels were used for the combustion analysis. The different fuels used for comparison was Diesel and waste cooking oil biodiesel. The combustion analysis was conducted with the help of species transport, in Ansys work bench. The temperature distribution of diesel and waste cooking oil biodiesel is shown in the Figure 8 \& Figure 9. From the Species transport analysis it was found that the piston temperature in the condition of diesel fuel was $2600 \mathrm{C}$ and in the condition of waste cooking oil biodiesel it was $273.40 \mathrm{C}$.

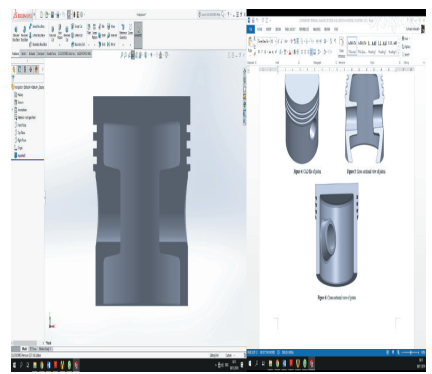

(a)

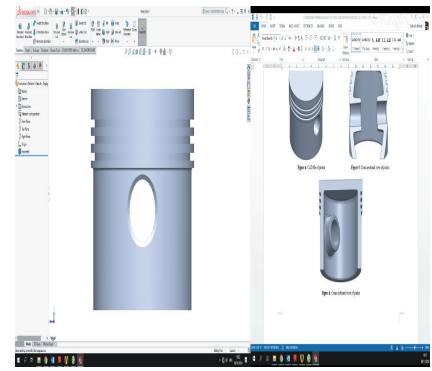

(b)

Figure 7. CAD File of piston, with different views

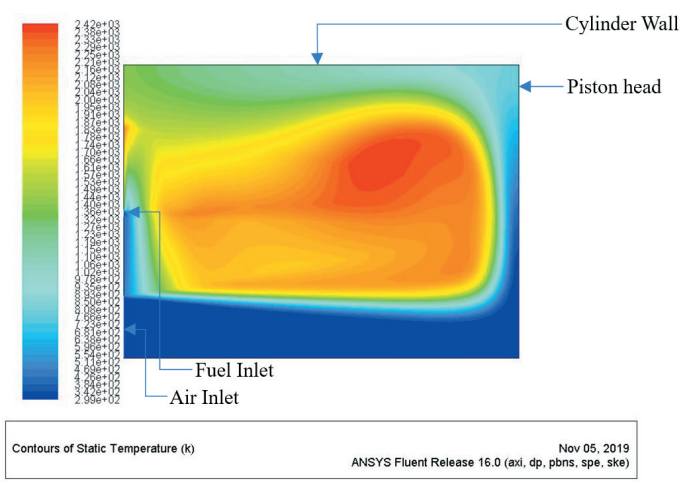

Figure 8. Combustion chamber of diesel 


\section{STEADY STATE THERMAL ANALYSIS \& THERMAL CONDITONS}

Steady state thermal analysis is similar to transient thermal analysis. Because both the analysis are similar, process for the analysis are also similar. In transient thermal analysis the load is a function of time, steady state thermal analysis the load is not a function of time. Steady state thermal analysis was carried out in Ansys V16 workbench, and cad file was imported from solidworks 2017. The element size of meshing was considered to be $1 \mathrm{~mm}$ and the minimum

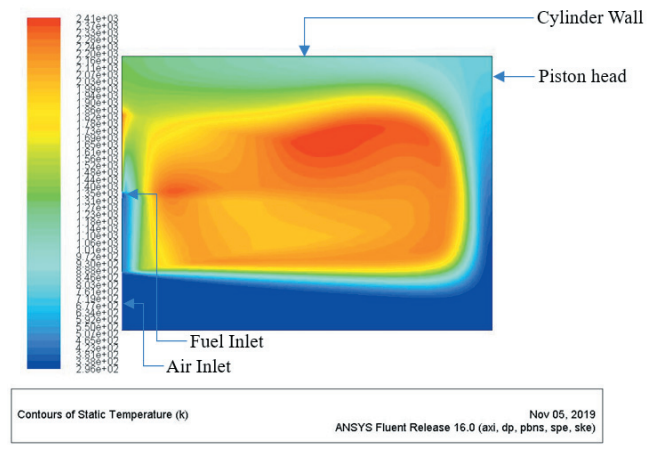

Figure 9. Combustion chamber of waste cooking oil Biodiesel

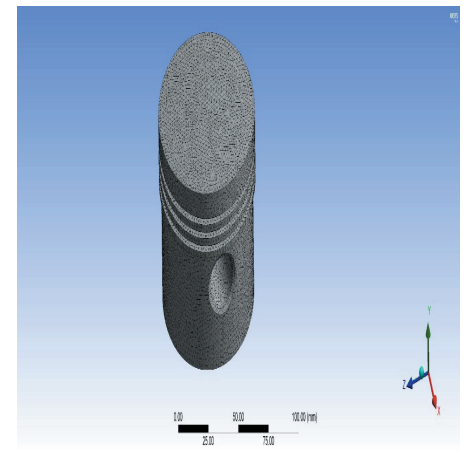

Figure 10. Meshed model of piston

Table 2. Thermal Conditions

\begin{tabular}{|c|c|}
\hline Thermal Properties & Value \\
\hline Heat Transfer Coefficient For Convection & $750 \mathrm{~W} / \mathrm{m}^{2}{ }^{\circ} \mathrm{C}$ \\
\hline Outer Piston Convection & $2330 \mathrm{~W} / \mathrm{m}^{2}{ }^{\circ} \mathrm{C}$ \\
\hline Emissivity & 0.44 \\
\hline
\end{tabular}

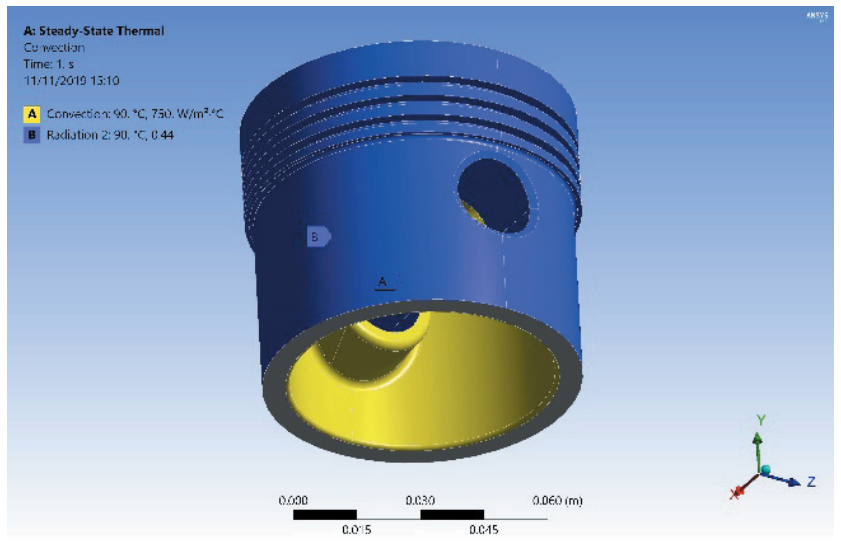

Figure 11. Inner Convection, \& Radiation boundary condition on the piston 
edge length was $1.07580 \mathrm{~mm}$. Meshed model of the piston is shown in Figure 10. Important parameters for conducting thermal analysis are the thermal emissivity and conductivity. Thermal emissivity and conductivity were gathered from literature review and have been compiled in Table 2. Thermal boundary conditions (i.e. radiation and convection) are depicted in the Figure 11.

\section{RESULT AND DISCUSSION}

Simulation was executed at the piston. The upper surface of the piston was ramped up to $260^{\circ} \mathrm{C}$ and $253 \mathrm{oC}$ for diesel and waste cooking oil biodiesel. The upper surface temperature piston was calculated by the finite element analysis, using species transport. As the piston is in a closed chamber, we only considered heat transfer coefficient for convection and emissivity. The highest temperature of the piston in case of Diesel was $260^{\circ} \mathrm{C}$ and the temp at the $3 \mathrm{rd}$ ring was $114^{\circ} \mathrm{C}$. Where as in the condition of using the biodiesel, the highest

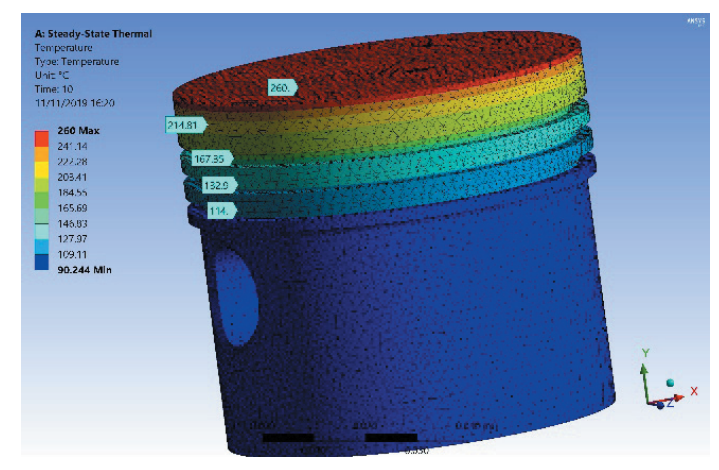

Figure 12. Temperature distribution of piston by diesel combustion

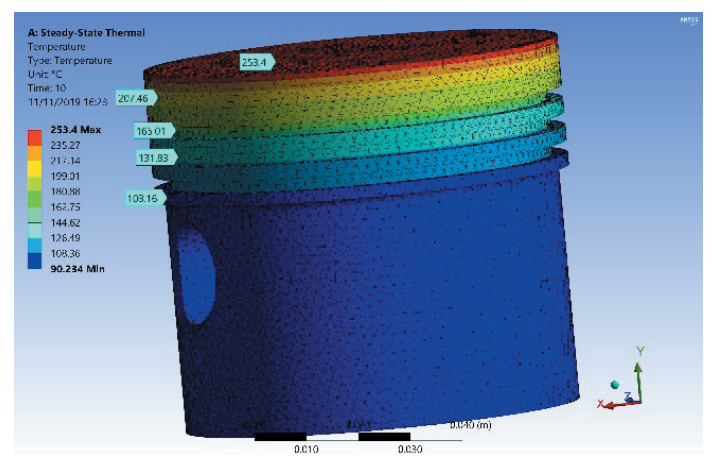

Figure 13. Temperature distribution of piston by bio-diesel combustion

temperature was $273.40 \mathrm{C}$ and the temperature at the $3 \mathrm{rd}$ ring was $126.160 \mathrm{C}$. The lowest temperature was on the piston skirt. The variation of the temperature was gradual shown in Figure 12 and Figure 13. The change in temperature in the piston with diesel and waste cooking oil biodiesel fuel depicted that the stresses developed by the piston in case of biodiesel was less.

\section{CONCLUSION}

It was important to assess the temperature attained by the piston to assess the maximum and minimum temperature points on the piston. The temperature spreading would help us in comparing the life of a piston in a longer run. Finite element analysis was conducted to forecast the maximum temperature on the piston crown. As the piston crown is the main contact surface in the combustion chamber. Piston crown indicated maximum temperature. For diesel the temperature at the piston was be $2600 \mathrm{C}$ and the temperature attained by the piston by waste cooking oil biodiesel was 273.40C. Species transport was used to compute the temperature. The temperature attained was used to predict the thermal distribution in the paper. The minimum temperature at 3rd ring of the piston for diesel was $1140 \mathrm{C}$ and for biodiesel was $126.160 \mathrm{C}$. There was a difference of $12.160 \mathrm{C}$ in the $3 \mathrm{rd}$ ring of the piston temperature and a difference of $13.40 \mathrm{C}$ at the piston crown. These temperature distributions would help us in computing the stress and deformation in the piston. 


\section{ACKNOWLEDGEMENT}

This work was supported by the research grant of the Kongju National University in 2021 \& this work was supported by the National Research Foundation of Korea (NRF) grant funded by the Korea government (MSIT) (NRF-2019R1A2C1010557)

\section{REFERENCES}

Rajesh Govindan, Dr. O.P. Jakhar, Dr. Y.B. Mathur. 2014. "Computational Analysis of Thumba Biodiesel-Diesel Blends Combustion in CI Engine Using Ansys - Fluent." International Journal of Computer \& Mathematical Sciences, 3: 29-39

Ahmed A. Al-Harbi, Feraih Sh. Alenazey, Saud A. Binjuwair, Ibrahim A. Alshunaifi, Abdullah M. Alkhedhair, Abdullah J. Alabduly, Mohammed S. Almorat and Miqad S. Albishi. 2020. "Effect of adding hydrogenrich synthesis gas and ethanol on NOx emissions with gasoline at different air/fuel mixtures." Journal of Engg. Research, 8(1): 1-16.

V G Cioată, I Kiss, V Alexa, S A Rațiu. 2017. "Mechanical and thermal analysis of the internal combustion engine piston using Ansys." IOP Conf. Series: Materials Science and Engineering, 1-11

Mika Nuutinen, Ossi Kaario and Martti Larmi. 2008. "Conjugate Heat Transfer in CI Engine CFD Simulations." SAE World Congress \& Exhibition.

Asif Afzal, Mohammed Kareemullah, Abdul Razak R.K. 2018. "Production of biodiesel from various sources and comparative engine performance studies by using different biodiesel blends." Journal of Engineering Research, 6(4): $1-21$.

A.R. Bhagat, Y. M. Jibhakate. 2012. "Thermal Analysis And Optimization Of I.C. Engine Piston Using Finite Element Method.” International Journal of Modern Engineering Research, 2; 2919-2921.

Shoichi Furuhama, Hidekazu Suzuki. 1979. "Temperature Distribution of Piston Ring and Piston in high speed diesel engine." Bulletin of the JSME, 22; 1788-1795.

Dallwoo Kim, Akemi Ito, Yasuhiro Ishikawa, Katsuyuki Osawa, Yoshiyuki Iwasaki. 2012. "Friction Characteristics of Steel Pistons for Diesel Engines.” Journal of Materials Research and Technology, 1(2); 96-102.

Ajay V. Kolhe, Rajesh E. Shelke, S. S. Khandare. 2015. "Combustion Modeling with CFD in Direct Injection CI Engine Fuelled with Biodiesel.” Jordan Journal of Mechanical and Industrial Engineering, 9; 61-66.

Hidehiko Kajiwara, Yukihiro Fujioka, Tatsuya Suzuki, Hideo Negishi. 2002. "An analytical approach for prediction of piston temperature distribution in diesel engines.” JSAE Review, 23; 429-434.

Magín Lapuerta, José M. Herreros, Lisbeth L. Lyons, Reyes García-Contreras, Yolanda Briceño. 2008. "Effect of the alcohol type used in the production of waste cooking oil biodiesel on diesel performance and emissions." Fuel, 87; 3161-3169.

Cheng Tung Chong, Bo Tian, Jo-Han Ng, Luming Fan, Shiyao Ni, Kang Yao Wong, Simone Hochgreb. 2020. "Quantification of carbon particulates produced under open liquid pool and prevaporised flame conditions: Waste cooking oil biodiesel and diesel blends." Fuel, 270; 1-10.

Ali M.A. Attia, Ahmad E. Hassaneen. 2016. "Influence of diesel fuel blended with biodiesel produced from waste cooking oil on diesel engine performance." Fuel, 167; 316-328. 
S. Senthur Prabu, M.A. Asokan, Rahul Roy, Steff Francis \& M.K. Sreelekh. 2017. "Performance, combustion and emission characteristics of diesel engine fuelled with waste cooking oil bio-diesel/diesel blends with additives." Energy, 122; 638-648.

Daniel P. Madison, Scott A. Miers, Glen. L Barna, Jay L Richerson. 2013. "Comparison of Piston Temperature Measurement Methods: Tempiugs Versus Wireiess Teiemetry With Thermocoupies.” Journal of Engineering for Gas Turbines and Power, 135; 061602-1-0616028.

Mahdi Hamzehei, Manochehr Rashidi. 2006. "Determination of Piston and Cylinder Head Temperature Distribution in a 4-Cylinder Gasoline Engine at Actual Process." Proceedings of the 4th WSEAS Int. Conf. on Heat Transfer, Thermal Engineering and Environment, 153-158.

J.H. Ong. 1990. "Steady State Thermal Analysis of a Diesel Engine Piston" Computers in Industry, 15; 255-258. 